\title{
Clinical significance of CC16 and IL-12 in bronchoalveolar lavage fluid of various stages of silicosis
}

\author{
Suhua Zhang ${ }^{1}$, Qiang Jia ${ }^{2}$, Junhua Song ${ }^{1}$, Qitao Tan $^{1}$, Gongchang Yu ${ }^{2}$, Xinfeng Guo ${ }^{1}$, Hongxiang Zhang ${ }^{1}$ \\ ${ }^{1}$ Department of Laboratory, Zibo Prevention and Treatment Hospital for Occupational Diseases, Zibo, China; ${ }^{2}$ Shandong Academy of Occupational \\ Health and Occupational Medicine, Shandong First Medical University \& Shandong Academy of Medical Sciences, Jinan, China \\ Contributions: (I) Conception and design: S Zhang; (II) Administrative support: H Zhang; (III) Provision of study materials or patients: J Song; (IV) \\ Collection and assembly of data: Q Jia; (V) Data analysis and interpretation: G Yu; (VI) Manuscript writing: All authors; (VII) Final approval of \\ manuscript: All authors. \\ Correspondence to: Hongxiang Zhang. Department of Laboratory, Zibo Prevention and Treatment Hospital for Occupational Diseases, Zibo, China. \\ Email: zbzhx0515@126.com.
}

Background Identification of novel biomarkers for silicosis could be helpful for disease diagnosis and pathophysiological mechanism exploration. Our study aims to investigate the Clara cell secretory 16-kd protein (CC16) and interleukin-12 (IL-12) levels in bronchoalveolar lavage fluid (BALF) in patients with silicosis at various stages.

Methods: The enzyme-linked immunosorbent assay (ELISA) double antibody sandwich method was used to determine the CC16 and IL-12 in BALF levels from 79 patients with silicosis of various stages. Correlation analyses were performed between CC16 and IL-12 levels, and lung function and cytological counts in patients with silicosis at various stages.

Results: There were no significant differences in the BALF recovery volume, the number of cells, percentages of macrophages and lymphocytes in the alveolar lavage fluid of patients with silicosis in different stages $(\mathrm{P}>0.05)$; the percentage of neutrophils in stage I and stage II were higher than the control group $(\mathrm{P}<0.05)$ with statistically significant differences. The CC16 in BALF levels in stage I and II silicosis groups lower than the control group and stage III silicosis group with statistically significant differences $(\mathrm{P}<0.05)$, whereas CC16 levels in stage II silicosis group are higher than the stage I group $(\mathrm{P}<0.01)$. The IL-12 levels were higher than the control group $(\mathrm{P}<0.01)$, and the IL-12 levels in stage II and III silicosis group was higher than the stage I silicosis group $(\mathrm{P}<0.01)$. With the increase of the length of dust service, the CC16 and IL-12 levels decreased and showed a positive correlation between these indexes (correlation coefficient $\mathrm{r}=0.559, \mathrm{P}<0.01)$. In addition, CC16 silicosis patient levels were positively correlated with FEV1/FVC and VCmax $(r=0.242,0.257$; both $\mathrm{P}<0.05)$; IL-12 levels were negatively correlated with FEV1 and VC max ( $\mathrm{r}=-0.250,-0.483$; both $\mathrm{P}<0.05)$.

Conclusions: The CC16 and IL-12 levels may have a specific reference value for the early diagnosis of silicosis and the assessment of lung function.

Keywords: Clara cell secretory 16-kd protein (CC16); interleukin-12 (IL-12); silicosis; bronchoalveolar lavage fluid (BALF)

Submitted Aug 12, 2020. Accepted for publication Nov 12, 2020.

doi: 10.21037/apm-20-1838

View this article at: http://dx.doi.org/10.21037/apm-20-1838 


\section{Introduction}

Silicosis, the most severe type of pneumoconiosis, is an interstitial lung disease caused by the inhalation of crystalline silica powder and is characterized by its fundamental pathological changes of diffuse fibrosis of the lungs and the formation of silicosis nodules. The mechanism of silicosis is hugely complicated, including immune-inflammatory response, cytotoxicity, oxidative stress, among many others. Several treatment choices including whole lung lavage, immunosuppression and antifibrotic therapy are suggested for silicosis (1), however, there is no specific treatment modality for silicosis. It is necessary to discover the novel biomarker for early disease diagnosis and mechanism exploration.

CC16 (also known as CC10) is a protein secreted by Clara cells and arranged on the mucosa of the respiratory tract $(2,3)$. CC16 could exert multiple physiological effects, including anti-inflammatory, antioxidant, antifibrosis, immune regulation, among many others (4). Moreover, IL-12 is critical cytokine with the effects of inflammation (5). Here, we examined Clara cell secretory 16-kd protein (CC16) and interleukin-12 (IL-12) in bronchoalveolar lavage fluid (BALF) in patients with silicosis at different stages and assessed their roles in the occurrence and development of silicosis. We present the following article in accordance with the MDAR reporting checklist (available at http://dx.doi.org/10.21037/apm-201838).

\section{Methods}

\section{Subjects}

A convenient sampling method was used to select silicosis patients who underwent bronchoalveolar lavage for the first time in Zibo Occupational Disease Prevention and Treatment Hospital from June 2015 to January 2018. The staging of silicosis was determined by the diagnosis criteria of occupational pneumoconiosis (GBZ70-2015) for collective diagnosis. Inclusion criteria: (I) meet the diagnosis criteria of "Diagnosis of Occupational Pneumoconiosis" (GBZ70-2015) and diagnosed as silicosis; (II) male without smoking history; (III) patients with informed consent and voluntarily participate in the study. Exclusion criteria: (I) patients with organic and infectious diseases such as tuberculosis or heart or liver or kidney diseases; (II) those who suffer from diseases such as the immune system and endocrine system or who have recently received treatment that affects immune and endocrine functions. Among the final included subjects, 41 patients with stage I silicosis, 25 patients with stage II silicosis, and 13 patients with stage III silicosis; ages from 33 to $67(48.6 \pm 3.9)$ years, and length of service from 5 to $27(12.7 \pm 6.5)$ years. Simultaneously, 20 cases of pneumoconiosis-free workers with similar work age and type of work undergoing bronchoalveolar lavage examination due to chest pain or cough were selected as controls (the X-ray chest radiograph of workers with silica dust service could not determinate pneumoconiosislike changes, but did not reach the stage I silicosis). Also, due to the risk of alveolar lavage for a normal person, no normal controls were set in the present study. The age of the control group was 34-65 $(47.4 \pm 6.3)$ years, and the length of dust service was $4-28(11.9 \pm 4.1)$ years. None of the selected subjects had pulmonary tuberculosis, no heart, liver, kidney, or other organic or infectious diseases. They were all male and had no history of smoking. The Ethics Committee approved this study of the Zibo Occupational Disease Prevention and Treatment Institute and the study conformed to the provisions of the Declaration of Helsinki (as revised in 2013), and all the subjects signed the written informed consent. After comparison, there was no significant difference in age and the length of dust service between the control group and the silicosis group $(\mathrm{t}=1.072$, $0.523 ; \mathrm{P}=0.286,0.601)$.

\section{BALF specimen collection}

The two groups of subjects underwent lung lavage treatment after the bronchoscopic examination of the airways and before biopsy brushing. The operation procedures of bronchoscopy standard procedures were followed strictly, and one lung lobe was lavaged each time. When the bronchoscopy reached the lavage site, 20$30 \mathrm{~mL}$ of $0.9 \% \mathrm{NaCl}$ prewarmed at $37{ }^{\circ} \mathrm{C}$ were injected each time for washing, and a total of 10 times and about $200 \mathrm{~mL}$ lavage fluid was recovered with negative pressure. After thoroughly mixing the recovered BALF, $30 \mathrm{~mL}$ were collected to centrifuge at 1,800-2,000 r/min for $10 \mathrm{~min}$, and the supernatant was collected and stored at $-20{ }^{\circ} \mathrm{C}$ for the further experiment of cytokine determination.

\section{ELISA detection for CC16 and IL-12 level determination}

ELISA detection was used for BALF, CC16, and IL12 determination in controls and patients with silicosis at various stages, and all the procedures were performed 
according to the manufacturer's instructions. TSZ produced all the kits in the United States. Briefly, Samples, including standards of known target protein concentrations and unknowns are pipetted into these wells. During the first incubation (room temperature for $1 \mathrm{~h}$ ), the target protein antigen and a biotinylated monoclonal antibody specific for target protein are simultaneously incubated. After washing, the enzyme (streptavidin-peroxidase) is added. After incubation (room temperature for $1 \mathrm{~h}$ ) and washing to remove the entire unbound enzyme, a substrate solution which is acting on the bound enzyme is added to induce a colored reaction product. The intensity of this colored product is directly proportional to the concentration of target protein present in the samples.

\section{BALF derived cell classification}

Cell classification and counting were performed according to the "Technical Specification for Bronchoalveolar Lavage Cytology Detection of the Chinese Medical Association Respiratory Branch (Draft)" (6). For cell count: After measurement of the recovered BALF volume, a small amount of BALF are placed on a cell counting plate, and all cells except epithelial cells and red blood cells (macrophages, lymphocytes, granulocytes, etc.) are counted under a microscope under 400 times magnification. The number was expressed as the number of cells per milliliter. For cell classification: BALF was filtered using a single layer of gauze and centrifuged at 1,800-2,000 r/min for 10 minutes. Then the supernatant was discarded and smears was made using the cells. After the smear was applied with Wright-Giemsa, at least 200 cells were counted under oil microscope for classification.

\section{Pulmonary function test}

The same technician performed the pulmonary function test using the Type Masterscreen-Bbdy/Diff lung function meter (Germany). The forced expiratory volume in 1 second $\left(\mathrm{FEV}_{1}\right)$, the ratio of the force expiratory volume in 1 second, and forced vital capacity $\left(\mathrm{FEV}_{1} / \mathrm{FVC}\right)$, and the vital capacity $\left(\mathrm{V}_{\mathrm{C}} \mathrm{max}\right)$ were recorded.

\section{Statistical analysis}

SPSS18.0 statistical software was used for analysis. Mean \pm standard deviation expressed the measurement data (SD) and compared using one-way ANOVA, followed by a Q test for pairwise comparison. $\mathrm{P}<0.05$ shows that the difference was statistically significant.

\section{Results}

Contents of lung lavage fluid in controls and patients with various stages of silicosis There was no significant difference in the recovered volume of BALF, the number of cells, the percentage of macrophages and lymphocytes in the alveolar lavage fluid from patients with silicosis at different stages $(\mathrm{P}>0.05)$. The percentage of neutrophils in the silicosis I and II stage group was higher than that in the control group, and the difference showed statistically significant $(\mathrm{T}=2.827,2.501 ; \mathrm{P}=0.006,0.016$; Figure 1$)$.

\section{BALF levels derived CC16 and IL-12 and lung function status of controls and silicosis patients of various stages}

As shown in Figure 2, compared with the control group, the CC16 in BALF levels in different stages of the silicosis group was lower, and the difference was statistically significant ( $\mathrm{T}=7.760,2.086 ; \mathrm{P}=0.000,0.043)$. Moreover, CC16 levels in the stage III group are higher than that in the control group, but without statistically significant ( $\mathrm{T}=1.060, \mathrm{P}=0.297)$. Also, CC16 levels in stage I and II groups are lower than that in the stage III group (I $v s$. III, $\mathrm{T}=9.007$, I vs. II, $\mathrm{T}=3.805$; I vs. III, $\mathrm{P}=0.000$, I vs. II, $\mathrm{P}=0.001$ ), whereas CC16 levels in the stage II group were higher than that in the stage I group $(\mathrm{T}=7.140, \mathrm{P}=0.000)$ with statistically significant differences. The IL-12 levels in BALF in stage I, II and III silicosis groups were higher than those in the control group (I vs. control $\mathrm{T}=15.051$, II vs. control $\mathrm{T}=15.659$, III $v s$. control $\mathrm{T}=116.372$; all the $\mathrm{P}$ values $<0.000$ ), and the IL-12 levels in stage II and III were higher than those in the stage I group (I vs. III, $\mathrm{T}=0.194$, I vs. II T=5.161; both of the $\mathrm{P}$ values are $<0.000$ ). The pulmonary function indexes $\mathrm{FEV}_{1}, \mathrm{FEV} 1 / \mathrm{FVC}$, and VCmax of stage I, II and III silicosis groups were all lower than those of the control group, and the differences were statistically significant [(I vs. control $\mathrm{T}=10.305$, II vs. control $\mathrm{T}=10.688$, III $v$ s. control $\mathrm{t}=8.305$; all the $\mathrm{P}$ values $<0.000$ ), (I vs. control $\mathrm{T}=2.376$, II vs. control $\mathrm{T}=4.642$, III vs. control $\mathrm{T}=6.248$; I vs. control $\mathrm{P}=0.021$, II $v s$. control $\mathrm{P}<0.000$, III vs. control $\mathrm{P}<0.000$ ), (I vs. control $\mathrm{T}=7.998$, II vs. control $\mathrm{T}=12.074$, III vs. control $\mathrm{T}=7.553$; all the $\mathrm{P}$ values $<0.000$ )] (Figure 3). 

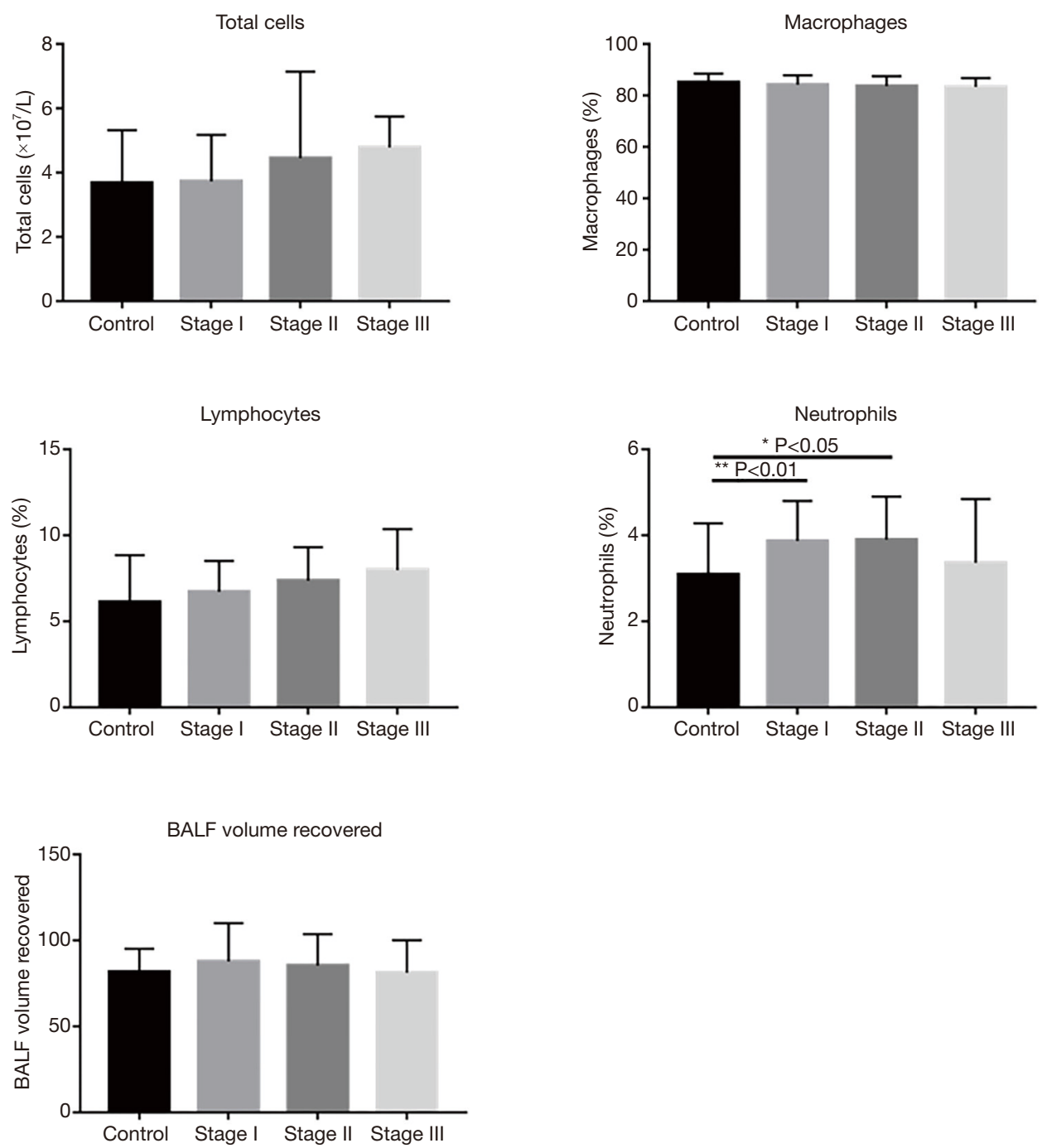

Figure 1 Contents of lung lavage fluid in controls and patients with distinct stages of silicosis. *, $\mathrm{P}<0.05$ and **, $\mathrm{P}<0.01$ for between group comparison. BALF, bronchoalveolar lavage fluid.

\section{Correlation between CC16 and IL-12 levels in BALF in silicosis group and related lung function indexes}

As shown in Table 1, in 79 silicosis patients CC16 levels were positively correlated with $\mathrm{FEV}_{1} / \mathrm{FVC}$ and VCmax $(\mathrm{r}=0.242,0.257 ; \mathrm{P}=0.032,0.022)$; IL-12 levels were negatively correlated with FEV1 and VCmax ( $\mathrm{r}=-0.250$, $-0.483 ; \mathrm{P}=0.026,0.000)$.

\section{Changes of CC16 and IL-12 levels in BALF with different length of dust service}

The control group and the silicosis group were divided into three groups following the dust exposure time; then, CC16 and IL-12 levels were compared. The results were shown in Table 2. The CC16 and IL-12 levels in BALF of silicosis patients in the $<10$ years group were higher than those in the 10-20 years group and $>20$ years group $[(t=7.125,7.558$; both of $\mathrm{P}$ values were $<0.000),(\mathrm{t}=5.768,11.254$; all the $\mathrm{P}$ values $<0.000)$ ] with statistically significant differences. Correlation analysis showed there was a positive correlation between CC16 and IL-12 levels and length of dust service in the silicosis group (correlation coefficient $\mathrm{r}=0.559$, $\mathrm{P}<0.01)$. In the control group, the CC16 and IL-12 levels among the different length of dust service groups showed no statistically significant differences $(\mathrm{P}>0.05)$. 

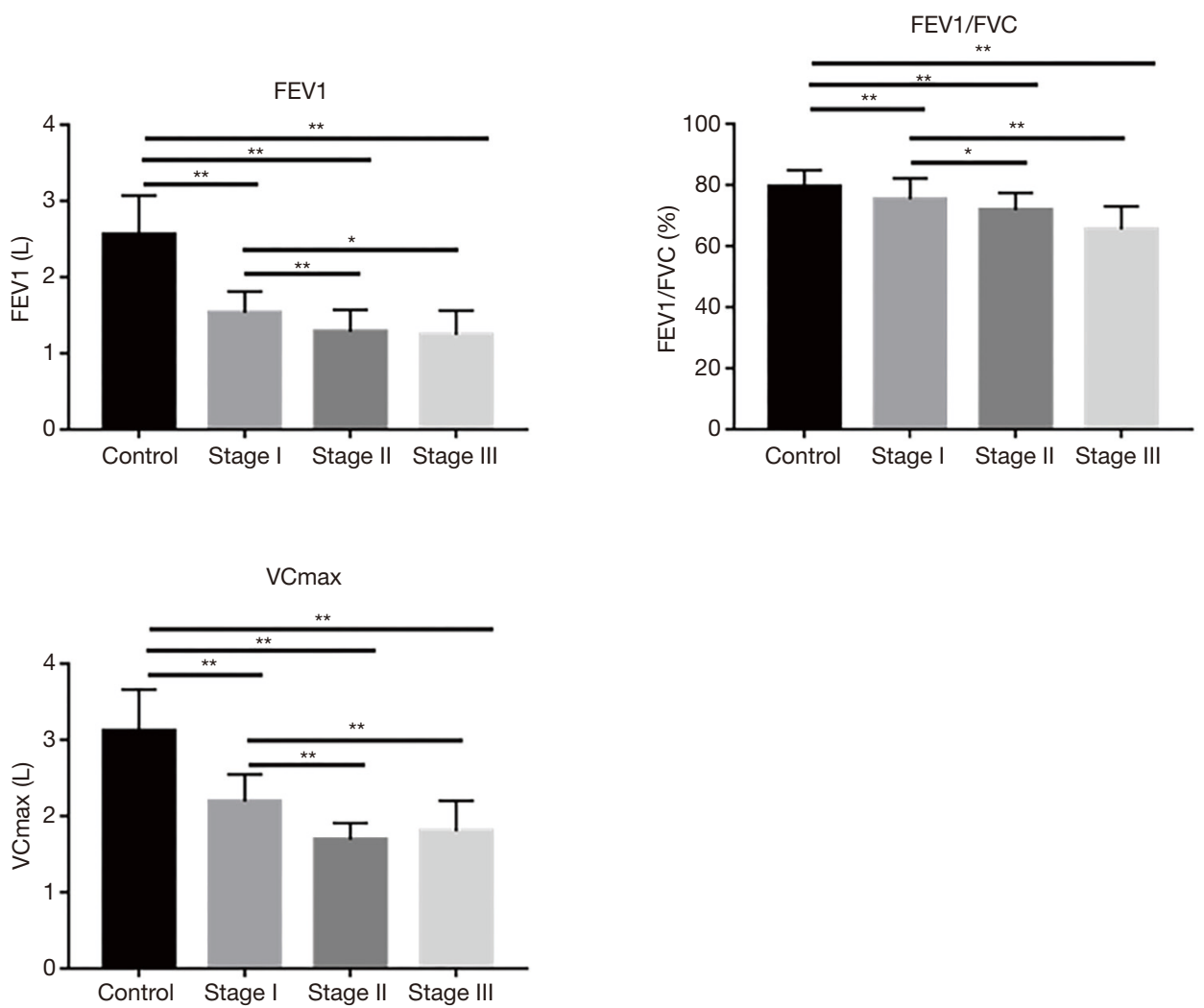

Figure 2 Lung function test results in controls and patients with various stages of silicosis. *, $\mathrm{P}<0.05$ and ${ }^{* *}, \mathrm{P}<0.01$ for between group comparison.
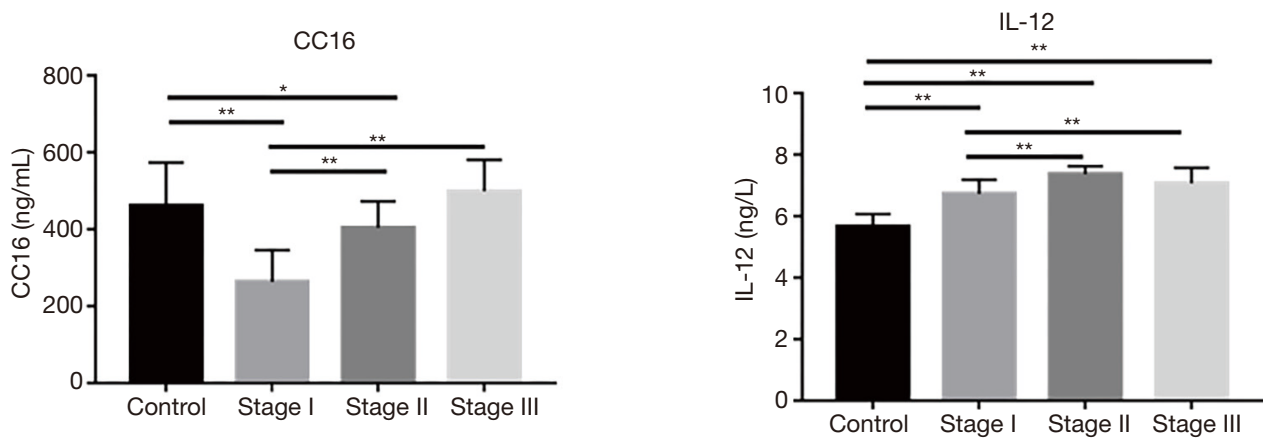

Figure 3 CC16 and IL-12 levels in controls and patients with various stages of silicosis. *, $\mathrm{P}<0.05$ and **, $\mathrm{P}<0.01$ for between group comparison.

\section{Correlation between CC16 and IL-12 levels in silicosis group and content indexes of lung lavage fluid}

Among 79 silicosis patients in stages I, II and III, the CC16 and IL-12 levels were not significantly correlated with the total cell number, the percentage of macrophages, neutrophils and lymphocytes [(CC16: $r=0.206,0.165,0.207$,

\author{
0.215; all P>0.05), (IL-12: r=0.102, -0.132, 0.172, -0.120, \\ all $\mathrm{P}>0.05)$ ] (Table 3).
}

\section{Discussion}

CC16 (also known as CC10) is a protein secreted by Clara 
Table 1 Correlation between CC16 and IL-12 levels and the lung function test indexes

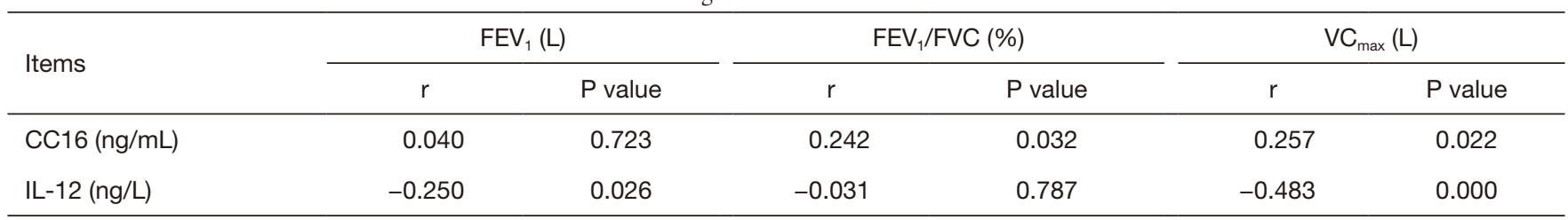

Table 2 CC16 and IL-12 levels in controls and patients stratified by length of service

\begin{tabular}{|c|c|c|c|c|c|c|}
\hline Mean length of service & \multicolumn{3}{|c|}{ Controls } & \multicolumn{3}{|c|}{ Silicosis } \\
\hline$<10$ yrs & 5 & $495.74 \pm 107.82$ & $5.64 \pm 0.12$ & 23 & $472.80 \pm 86.66^{b}$ & $7.88 \pm 0.49^{b}$ \\
\hline $10-20$ yrs & 9 & $473.21 \pm 68.11$ & $5.66 \pm 0.21$ & 37 & $319.45 \pm 77.43^{*}$ & $6.98 \pm 0.64^{*}$ \\
\hline$>20$ yrs & 6 & $472.23 \pm 102.61$ & $5.60 \pm 0.15$ & 19 & $280.45 \pm 76.14^{*}$ & $6.29 \pm 0.41^{\star b}$ \\
\hline$P$ value & - & 0.876 & 0.783 & - & 0.000 & 0.000 \\
\hline
\end{tabular}

${ }^{*}, \mathrm{P}<0.05$ compared to the control group; ${ }^{\mathrm{b}}, \mathrm{P}<0.01$ compared to stage I patients.

Table 3 Correlation between CC16 and IL-12 levels and content indexes of lung lavage fluid

\begin{tabular}{|c|c|c|c|c|c|c|c|c|}
\hline Items & \multicolumn{2}{|c|}{ Total cells $\left(\times 10^{7} / L\right)$} & \multicolumn{2}{|c|}{ Macrophages (\%) } & \multicolumn{2}{|c|}{ Lymphocytes (\%) } & \multicolumn{2}{|c|}{ Neutrophils (\%) } \\
\hline CC16 (ng/mL) & 0.206 & $>0.05$ & 0.165 & $>0.05$ & 0.207 & $>0.05$ & 0.215 & $>0.05$ \\
\hline IL-12 (ng/L) & 0.102 & $>0.05$ & -0.132 & $>0.05$ & 0.172 & $>0.05$ & -0.120 & $>0.05$ \\
\hline
\end{tabular}

cells and arranged on the mucosa of the respiratory tract. From its nearly $16 \mathrm{kD}(15,840 \mathrm{D})$ molecular weight, it is named CC16 and is mainly expressed in lung tissues $(2,3)$. CC16 could exert multiple physiological effects, including anti-inflammatory, antioxidant, anti-fibrosis, immune regulation, among many others (4). The primary function of Clara cells is to function as progenitor cells during the repair of respiratory tract epithelial injury. The decrease of this type of cell attributes to the main reason for the decrease of CC16 in BALF. Airway inflammation can reduce the number of Clara cells, and the degree of reduction can early reflect the damage to bronchiolar mucosal epithelial cells (7). Our data showed that CC16 levels in BALF in stage I and II silicosis groups were lower than those in the control group $(\mathrm{P}<0.05)$, which is consistent with the report by Liu et al. (8). Varying degrees of damage to the Clara cells of patients could lead to the weakening of their endogenous anti-inflammatory function. The possible reason is that silica dust can directly cause inflammatory damage to the lungs, and with the prolongation of dust exposure, inflammation will gradually increase, resulting in Clara cell damage and decreasing of CC16 secretion. Also, after exposure to silica dust, the toxins released by activated phagocytes, the toxic effects of silica dust, and free radicals will damage Clara cells, thereby reducing the secretion of CC16. The reduction of its secretion quantity will attenuate the inhibitory effect of certain pro-inflammatory factors, leading to aggravation of inflammation, which in turn further aggravates the damage to Clara cells.

Our data also showed the CC16 levels in BALF in each stage of silicosis are not only lower than that in the control group $(\mathrm{P}<0.05)$, but also lower than that in the stage III group $(\mathrm{P}<0.05)$. A trend of the increase was found in stage I, II, and III silicosis patients, and although CC16 in the stage III group was higher than in the control group, no statistical significance was found $(\mathrm{P}>0.05)$. The reason may attribute to the self-repairing effect of respiratory epithelial cells, the compensation effects of CC16, and the 
antioxidant effect (9), further studies might be performed to determine the other factors, including microbronchial and alveolar wall structural barrier destruction, fibrosis, and enhanced protein filtration rates. Studies have shown that the reduction of serum CC16 is an important marker to distinguish COPD and healthy controls, and is related to the degree of COPD airflow limitation (10). Duan et al. (11) also believed that decreasing the number of Clara cells and functional damage in patients with silicosis, and the decreased serum CC16 level can be used as a signature of early diagnosis of silicosis. Moreover, our data also showed CC16 levels in BALF in patients with silicosis were positively correlated with $\mathrm{FEV}_{1} / \mathrm{FVC}$ and $\mathrm{VCmax}(\mathrm{r}=0.242$, 0.257 , both $\mathrm{P}<0.05)$; these findings are consistent with previous reports (12). It suggests CC16 also plays a key role in evaluation of the degrees of the disease, and CC16 may be involved in the occurrence and development of silicosis. Our study further showed that the percentage of neutrophils in stage I and II silicosis group was higher than that in the control group $(\mathrm{P}<0.05)$, which is also consistent with previous studies. Silica dust can result in a significant increase in the total number of white blood cells. In the early stages of silicosis, cellular nodules are formed, mainly composed of neutrophils and monocytes, and in the late stage, lymphocytes play the primary role, and the fibrotic nodules are presented (13). The possible reason is that when silica dust enters the alveolar cavity, it could produce a substantial number of inflammatory mediators and chemokines, which increases the permeability of capillaries. With many neutrophils entering the alveolar cavity, aggravation of the inflammation process, and many neutrophils in BALF could be observed (13).

IL-12 is considered to play a critical role in regulating the development of Th1 type cells, mainly produced by activated macrophages (14). IL-12 has various biological activities, including inflammation, Th1/Th2 mediated immune response balance regulation (5). IL-12 is a crucial Th1 type cytokine, and the imbalance between Th1 and Th2 type cells could result in tissue damage, inflammation, and fibrosis. Huaux et al. (15) showed that the stimulation of silica dust particles increased IL-12p40 levels in the lungs, thereby aggravating the formation of pulmonary fibrosis, indicating that IL-12p40 aggravation caused the recruitment of nuclear macrophages was related with the formation of pulmonary fibrosis. Our data also showed IL-12 levels in BALF from silicosis groups were higher than those of the control group, and the differences were statistically significant (all $\mathrm{P}<0.01$ ), which was consistent with the results of Zou et al. (16). The probable reason is the stimulation of silica dust particles that abnormally activates macrophages, thereby resulting in abnormally increased IL-12 secretion. Overexpression of IL-12 enhances the activity of T/NK cells and stops the stimulation. The stage II and III silicosis groups are significantly higher than the stage I silicosis group $(\mathrm{P}<0.01)$, which may be related to the inhibition of advanced pulmonary fibrosis resulting from IL-12, inducing the increasing activity of TH1 and NK cells (17). In addition, the self-compensation or protection that enhances the anti-fibrosis effect in the body can also lead to an increase in IL-12 levels. In addition, our data also showed IL-12 levels were negatively correlated with FEV1 and $\mathrm{VC} \max (\mathrm{r}=-0.250,-0.483$, both $\mathrm{P}<0.05)$, suggesting that IL-12 has a critical role in monitoring the condition of silicosis patients.

Also, our data showed the CC16 and IL-12 levels in BALF of silicosis patients in $<10$ years group were significantly higher than those in 10-20 years group and $>20$ years group $[(\mathrm{t}=7.125,7.558),(\mathrm{t}=5.768,11.254)]$ (all $\mathrm{P}<0.01)$. CC16 and IL-12 levels were higher in the initial stage of dust exposure, suggesting that they may play a vital role in the initial stage of inflammation. With the longterm continuation of dust exposure, both cytokine levels gradually decreased in BALF, and a positive correlation could be found between them (correlation coefficient $\mathrm{r}=0.559, \mathrm{P}=0.000$ ). Furthermore, our study also showed CC16, and IL-12 levels in BALF in patients with silicosis at various stages were positively correlated $(\mathrm{r}=0.326, \mathrm{P}=0.003)$, suggesting that CC16 and IL-12 may have a synergistic effect. Fisher et al. (18) found that CC16 can stimulate the production and activity of various inflammatory factors, including interferon- $\gamma(\mathrm{IFN}-\gamma)$, and the overexpression of IFN- $\gamma$ can up-regulate the expression of CC16. IL-12 can also activate $\mathrm{NK}$ cells and $\mathrm{T}$ lymphocytes to increase the secretion of IFN- $\gamma$, and the increase of IFN- $\gamma$ can activate the mononuclear macrophage system and cause the increase of IL-12. Combined monitoring of CC16 and IL-12 levels in BALF of patients with silicosis at distinct stages may be helpful for early diagnosis of silicosis and lung function assessment.

There is also some limitation in the present study. Firstly, we performed the stratified analysis by the age of patients to illustrate the changes in CC16 and IL-12 levels not performed due to the small sample size. Secondly, the mechanism of action still needs to be further studied. In follow-up studies, other biomarkers and sample sizes can be increased to explore further their role in the occurrence and 
development of silicosis and provide more clues and help for the prevention of silicosis.

In conclusion, we proved here that the CC16 and IL12 levels might have a specific reference value for the early diagnosis of silicosis and the assessment of lung function.

\section{Acknowledgments}

Funding: None.

\section{Footnote}

Reporting Checklist: The authors have completed the MDAR reporting checklist. Available at http://dx.doi.org/10.21037/ apm-20-1838

Data Sharing Statement: Available at http://dx.doi. org/10.21037/apm-20-1838

Conflicts of Interest: All authors have completed the ICMJE uniform disclosure form (available at http://dx.doi. org/10.21037/apm-20-1838). The authors have no conflicts of interest to declare.

Ethical Statement: The authors are accountable for all aspects of the work in ensuring that questions related to the accuracy or integrity of any part of the work are appropriately investigated and resolved. The Ethics Committee approved this study of the Zibo Occupational Disease Prevention and Treatment Institute and the study conformed to the provisions of the Declaration of Helsinki (as revised in 2013), and all the subjects signed the written informed consent.

Open Access Statement: This is an Open Access article distributed in accordance with the Creative Commons Attribution-NonCommercial-NoDerivs 4.0 International License (CC BY-NC-ND 4.0), which permits the noncommercial replication and distribution of the article with the strict proviso that no changes or edits are made and the original work is properly cited (including links to both the formal publication through the relevant DOI and the license). See: https://creativecommons.org/licenses/by-nc-nd/4.0/.

\section{References}

1. Yew WW, Leung CC, Chang KC, et al. Can treatment outcomes of latent TB infection and TB in silicosis be improved? J Thorac Dis 2019;11:E8-E10.

2. Manning CM, Johnston CJ, Hernady E, et al.

Exacerbation of lung radiation injury by viral infection: the role of Clara cells and Clara cell secretory protein. Radiat Res 2013;179:617-29.

3. Zhang $\mathrm{H}$, Wang $\mathrm{R}$, Wang $\mathrm{H}$, et al. Dynamic changes in expression of clara cell protein and surfactant protein-D expressions in lung tissues and bronchoalveolar lavage fluid of silica-treated rats. Zhonghua Lao Dong Wei Sheng Zhi Ye Bing Za Zhi 2014;32:168-72.

4. Briana DD, Gourgiotis D, Boutsikou M, et al. Clara cell protein in full-term pregnancies: the influence of intrauterine growth restriction. Pediatr Pulmonol 2010;45:1186-91.

5. Haskó G, Szabó C. IL-12 as a therapeutic target for pharmacological modulation in immune-mediated and inflammatory diseases: regulation of $\mathrm{T}$ helper $1 / \mathrm{T}$ helper 2 responses. Br J Pharmacol 1999;127:1295-304.

6. Chen YJ, Wang J. Clinical value of liquid-based cytology test in brushing examination of patients with lung cancer. Medical Recapitulate 2011;17:2686-8.

7. Song Y, Xiaoguang L, Chen L, et al. The expression and significance of protein AQP5 and CC16 in lung injury after hemorrhagic shock resuscitation in rats. Chinese Journal of Emergency Medicine 2017;26:1397-401.

8. Liu J, Song HY, Zhu BL, et al. The Effect of Silica Dust Exposure on the Serum Clara Cell Protein 16 Levels in Chinese Workers. Biomed Environ Sci 2019;32:47-50.

9. Halatek T, Opalska B, Rydzynski K, Bernard A. Pulmonary response to methylcyclopentadienyl manganese tricarbonyl treatment in rats: injury and repair evaluation. Histol Histopathol 2006;21:1181-92.

10. Rosenberg SR, Kalhan R. Biomarkers in chronic obstructive pulmonary disease. Transl Res 2012;159:228-37.

11. Duan H, Wang Y, Wang Z, et al. O3C. 5 Reduced serum clara cell protein (CC16) as an early pulmonary injury marker for fine particulate matter exposure in occupational population. BMJ Publishing Group Ltd, 2019.

12. Weston A. Work-related lung diseases. IARC Sci Publ 2011;163:387-405.

13. Porter DW, Hubbs AF, Mercer R, et al. Progression of lung inflammation and damage in rats after cessation of silica inhalation. Toxicol Sci 2004;79:370-80.

14. Hamza T, Barnett JB, Li B. Interleukin 12 a key immunoregulatory cytokine in infection applications. Int J Mol Sci 2010;11:789-806.

15. Huaux F, Arras M, Tomasi D, et al. A profibrotic function of IL-12p40 in experimental pulmonary fibrosis. J 
Immunol 2002;169:2653-61.

16. Zou J, du Prel Carroll X, Liang X, et al. Alterations of serum biomarkers associated with lung ventilation function impairment in coal workers: a cross-sectional study. Environ Health 2011;10:83.

17. Sakamoto H, Zhao LH, Jain F, et al. IL-12p40(-/-) mice treated with intratracheal bleomycin exhibit decreased

Cite this article as: Zhang S, Jia Q, Song J, Tan Q, Yu G, Guo X, Zhang H. Clinical significance of CC16 and IL-12 in bronchoalveolar lavage fluid of various stages of silicosis. Ann Palliat Med 2020;9(6):3848-3856. doi: 10.21037/apm-20-1838 pulmonary inflammation and increased fibrosis. Exp Mol Pathol 2002;72:1-9.

18. Fisher CE, Ahmad SA, Fitch PM, et al. FITC-induced murine pulmonary inflammation: CC10 up-regulation and concurrent Shh expression. Cell Biol Int 2005;29:868-76.

(English Language Editor: J. Chapnick) 